\title{
Mystery of Hepatitis E Virus: Recent Advances in Its Diagnosis and Management
}

\author{
Aftab Ahmed, ${ }^{1}$ Ijlal Akbar Ali, ${ }^{1}$ Hira Ghazal, ${ }^{2}$ Javid Fazili, ${ }^{3}$ and Salman Nusrat ${ }^{3}$ \\ ${ }^{1}$ Department of Internal Medicine, Oklahoma University Health Sciences Center, Williams Pavilion 1130, P.O. Box 26901, \\ Oklahoma City, OK 73104, USA \\ ${ }^{2}$ Dow Medical College, Mission Road, Karachi 74200, Pakistan \\ ${ }^{3}$ Section of Digestive Diseases and Nutrition, Oklahoma University Health Sciences Center, Williams Pavilion 1345, \\ 920 SL Young Boulevard, Oklahoma City, OK 73104, USA \\ Correspondence should be addressed to Salman Nusrat; salman-nusrat@ouhsc.edu
}

Received 28 September 2014; Accepted 27 December 2014

Academic Editor: Maria Buti

Copyright (C) 2015 Aftab Ahmed et al. This is an open access article distributed under the Creative Commons Attribution License, which permits unrestricted use, distribution, and reproduction in any medium, provided the original work is properly cited.

Mysterious aspects of the long presumed to be well-known hepatitis E virus (HEV) have recently surfaced that distinguish it from other hepatotropic viruses. It is a cause of chronic hepatitis in immunosuppressed patients. It has human to human transmission through blood and mantains high seroprevalence in blood donors. HEV has also been found to occur more frequently in the West in those without a history of travel to endemic countries. It has varied extrahepatic manifestations and has multiple non-human reservoirs including pigs and rats. Considering these recent discoveries, it appears odd that HEV is not sought more frequently when working up acute and chronic hepatitis patients. The disease is particularly severe among pregnant women and has a high attack rate in young adults. What adds to its ambiguity is the absence of a well-established diagnostic criteria for its detection and that there is no specific antiviral drug for hepatitis E, except for isolated cases where ribavirin or pegylated interferon alpha has been used with occasional success. This review paper discusses the recent advances in the knowledge of the virus itself, its epidemiology, diagnostic approach and prevention, and the treatment options available.

\section{Introduction}

In 1978 the existence of a non-A, non-B hepatitis virus, likely hepatitis E virus (HEV) was suggested during an outbreak of acute hepatitis in Kashmir [1-3]. However, it was not truly identified until 1983 when a researcher investigating an outbreak of unexplained hepatitis in Soviet soldiers in Afghanistan ingested fecal extract from affected military personnel and developed acute hepatitis and small viral particles were identified in his stool [3]. Recently, mysterious aspects of this once presumed to be well known virus have surfaced. Over the last few years our practices and understanding pertaining to its prevalence, mode of infection, clinical manifestations, diagnostic tests, treatment options, and role of vaccination have evolved tremendously. There is now good evidence that HEV infection is neither rare nor limited to developing countries and no clinical presentation is limited to acute infection (Table 2). Lack of knowledge among physicians and absence of standardized tests result in failure to diagnose and therefore can lead to an increase in morbidity and mortality. All this underscores the importance of HEV as a virus that might have taken us off guard.

\section{Virology and Taxonomic Status}

HEV is a small $(27-34 \mathrm{~nm})$ nonenveloped virus. The viral genome consists of a single-stranded, positive-sense RNA molecule organized into three open reading frames (ORF1, ORF2, and ORF3) (Figure 1). ORF1 is involved in viral replication and protein processing through RNA-dependent RNA polymerase. ORF2 encodes the viral capsid protein, which is involved in attachment to host cells and induction of neutralizing antibodies. Finally, ORF3 encodes for a small immunogenic phosphorylated protein (pORF3) involved in virion morphogenesis and release [4]. 


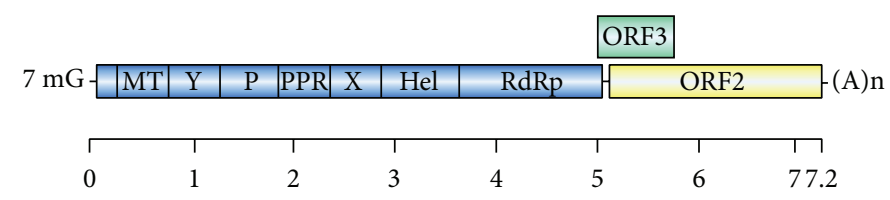

FIgURE 1: The structure of the hepatitis E virus genome. RNA length: $7.2 \mathrm{~kb}$. It has short 5 and 3 noncoding regions and three overlapping open reading frames (ORFs). ORF1 encodes the nonstructural proteins, including a methyl transferase (MT), cysteine protease (P), helicase (Hel), and RNA polymerase (RdRp), as well as three regions of unknown function (Y, PPR, and X). The 5 end of the RNA genome is capped with 7-methylguanosine $(7 \mathrm{mG})$, and the 3 end is polyadenylated (poly A).

It belongs to the Hepeviridae family and is the sole member of genus Hepevirus [5]. HEV genotypes are further classified into subtypes: genotype 1, five (1a-1e); genotype 2 , two ( $2 \mathrm{a}$ and $2 \mathrm{~b}$ ); genotype 3 , ten ( $3 a-3 j)$; and genotype 4 , seven $(4 \mathrm{a}-4 \mathrm{~g})$ [4]. Genotype 2 appears to be exclusively anthroponotic, while genotype 1 infects mainly humans but has also been detected in pigs [4, 6]. Genotypes 3 and 4 also infect other animals, particularly pigs (Table 1 ).

\section{Epidemiology}

$\mathrm{HEV}$ is one of the leading causes of hepatitis worldwide. Human infection with HEV is not only prevalent in developing countries but is also common in western nations and based on geographical distribution there are two distinct epidemiological patterns $[3,7]$.

3.1. Infection in Developing Countries. Hepatitis E has long been considered a disease of developing countries. Although lack of routinely available diagnostics tests and dual infection with HAV makes it difficult to estimate its true prevalence, some have reported a prevalence as high as 50\% [8]. Outbreak is more common during summer. For unclear reasons it predominantly affects males between the ages of 15 and 30 years and is uncommon in children younger than 10 years [3]. Genotype 1 tends to be more common in Southern and Central Asia; similarly others are more prevalent in other geographical locations (Table 1). HEV1 is prevalent in Southern and Central Asia, the Far East, North Africa, and the Caribbean. HEV2 is predominant in Mexico (probably subtype 2a) and West Africa (subtype 2b). HEV3 infections are found to occur worldwide, including America, Europe, China, and Japan and HEV4 predominates in China whilst also being detected in swine livestock from India and Indonesia and recently in Central Europe $[1,3,6,7,9,10]$. Increasing the complexity of the HEV epidemiology, HEV is occasionally associated with hepatitis A virus outbreaks in developing regions in the form of dual infection [6]. These waterborne outbreaks have been exclusively associated with genotypes 1 and 2 strains [6]. Due to the lesser stability of its particle, $\mathrm{HEV}$ is less prevalent in the population than HAV [9].

3.2. Infection in Developed Countries. In developed countries, $\mathrm{HEV}$ infection has traditionally been recognized among travelers returning from endemic countries. However, during the past decade, sporadic autochthonous (locally acquired) cases of HEV genotypes 3 and 4 infection have also been reported without recent travel history to endemic countries $[3,11]$, with a predilection for middle-aged elderly males aged over 40 (mean age 60 years; male/female ratio $=3: 1$ ) [3]. In contrast to prevalence in developing parts of the world, in non-endemic countries hepatitis $\mathrm{E}$ represents about $1 \%$ of the acute viral hepatitis $[7,12]$. As exposure appears to be unrelated to age or sex, it seems unconventional [13] and puzzling that older men are more often exposed to HEV and implies that host factors could be important [3]. HEV strains responsible for autochthonous infections have been isolated from various animal species including wild and domestic swine, deer, chicken, rats, rabbit [6], and camels [14], slurry lagoons, rivers, the sea, shellfish, and soft fruits [13]. Phylogenetic studies have proven the relationship between HEV strains circulating in pigs and human beings, thus promoting the notion of autochthonous zoonotic transmission [3].

\section{Mode of Transmission}

The fecooral route is the primary and most well documented mode of transmission. It is more prevalent with HEV-1 and -2 and explains the endemicity and frequent outbreaks of HEV-1 and -2 in developing countries $[7,15,16]$. Genotype 3 has been detected in pig liver in grocery stores and thus may partially account for HEV exposure in the United States [17].

In developed countries, some cases of vertical transmissions of HEV have been reported [4]. However, transmission through breast milk has not been described [6].

Recently transmission via blood transfusions has become a concern. Seroprevalence rates as high as $50 \%$ have been reported among asymptomatic individuals in nonendemic countries. Although not representative of active infection or carrier state, such high seropositive states in asymptomatic individuals raise concerns about the spread of infection during periods of infectivity particularly in the absence of standardized screening tests $[4,6]$.

$\mathrm{HEV}$ has recently been reported in homosexual men, which supports its sexual transmission $[18,19]$. Direct animal transmission is also a possibility as studies have shown that veterinarians and swine handlers have more chances to be anti-HEV IgG positive than the general population [3].

\section{Clinical Presentation}

Hepatitis E has variable clinical presentations and ranges from asymptomatic carriers to fulminant hepatitis. As one 
TABle 1: Epidemiology and clinical features of hepatitis E virus [3, 6, 10, 20, 21].

\begin{tabular}{|c|c|c|c|c|}
\hline Genotype & 1 & 2 & 3 & 4 \\
\hline Host & $\begin{array}{l}\text { Human; also isolated from } \\
\text { pig }\end{array}$ & Human exclusively & Hur & ther mammalian species \\
\hline $\begin{array}{l}\text { Route of } \\
\text { transmission }\end{array}$ & \multicolumn{2}{|c|}{ Fecal-oral; vertical transmission; zoonotic (genotype 1) } & $\begin{array}{l}\text { Zoonotic (u } \\
\text { hosts); envir } \\
\text { (shellfish, ri }\end{array}$ & $\begin{array}{l}\text { th humans being accidental } \\
\text { fusion }\end{array}$ \\
\hline $\begin{array}{l}\text { Geographical } \\
\text { distribution }\end{array}$ & $\begin{array}{l}\text { Mainly Asia and Latin } \\
\text { America (Cuba, } \\
\text { Venezuela, and Uruguay) }\end{array}$ & Mexico and West Africa & Worldwide & $\begin{array}{l}\text { China, East Asia, Central } \\
\text { Europe, and America }\end{array}$ \\
\hline $\begin{array}{l}\text { Epidemiological } \\
\text { features }\end{array}$ & $\begin{array}{l}\text { Causes epidemic } \\
\text { outbreaks and sporadic } \\
\text { cases in } \\
\text { developing countries; } \\
\text { occasionally in travelers } \\
\text { returning from developing } \\
\text { countries }\end{array}$ & $\begin{array}{l}\text { Causes epidemic } \\
\text { outbreaks and sporadic } \\
\text { cases } \\
\text { in developing countries }\end{array}$ & Causes spor & lous cases in developed countries \\
\hline Seasonality & \multicolumn{2}{|c|}{ Yes (outbreaks in flooding/monsoon) } & & No \\
\hline $\begin{array}{l}\text { Clinical } \\
\text { presentation }\end{array}$ & $\begin{array}{l}\text { Mostly asymptomatic; } \\
\text { acute self-limited hepatitis }\end{array}$ & $\begin{array}{l}\text { Mostly asymptomatic; } \\
\text { acute self-limited hepatitis }\end{array}$ & $\begin{array}{l}\text { Varies from } \\
\text { hepatitis an } \\
\text { immunosup }\end{array}$ & $\begin{array}{l}\text { o acute self-limited } \\
\text { ronicity in } \\
\text { HEV3) }\end{array}$ \\
\hline Age & \multicolumn{2}{|c|}{ Adolescents and young (15-30 y) } & & and elderly (>50 y) \\
\hline Gender $(M: F)$ & \multicolumn{2}{|c|}{$2: 1$} & & $>3: 1$ \\
\hline Prognosis & $\begin{array}{l}\text { High mortality in } \\
\text { pregnancy and in patients } \\
\text { with underlying chronic } \\
\text { liver disease }\end{array}$ & $\begin{array}{l}\text { Fulminant hepatitis has not } \\
\text { been noted in HEV2 }\end{array}$ & $\begin{array}{l}\text { Higher over } \\
\text { genotype } 1 ;\end{array}$ & $\begin{array}{l}\text { e relative to } \\
\text { among older adults }\end{array}$ \\
\hline Chronic infection & & No & Yes & Yes \\
\hline
\end{tabular}

TABLE 2: Individuals at higher risk of acute liver failure from HEV infection $[1,3,6,7,12,22-24]$.

Pregnant women

Individuals with preexisting liver disease

Hepatitis B virus carriers

Individuals with drug induced liver injuries

Active alcohol abusers

would expect clinical manifestations to some extent depend on the predominant genotype. In endemic areas where genotypes 1 and 2 are most prevalent it primarily manifests as acute hepatitis. On the other hand in developed countries genotypes 3 and 4 are more prevalent and patients are mostly asymptomatic [25]. This notion was supported by Kumar et al. who identified that all the acute cases resulted from subtype Ia and that the fulminant cases were secondary to subtype Ic [16]. However, Smith and Simmonds [26] in their study suggested that it is the host-specific factors rather than virus genotype that dictate the risk of fulminant hepatitis.

In acute $\mathrm{HEV}$, the incubation period is 3-8 weeks followed by a short prodromal phase. The symptomatic phase can last anywhere from days to several weeks (mean 4-6 weeks) [27]. As with acute hepatitis from other etiologies patients present with jaundice, right upper quadrant pain, and nondescript symptoms such as fever, asthenia, nausea, vomiting, and joint pains $[1,28,29]$. Recent data has shown that it is not uncommon that patients with acute hepatitis from HEV are misdiagnosed as having drug-induced liver injury [22]. $\mathrm{HEV}$ at times can infect patient with chronic liver disease; however a similar clinical picture makes diagnosis difficult and challenging $[7,13,23,30]$. This is particularly important as prognosis is grim in patients with preexisting chronic liver disease and some studies report a mortality rate as high as $70 \%$ [3]. Other risk factors for acute liver failure are noted in Table 1.

A wide range of extrahepatic manifestations have been attributed to HEV. Those associated with acute illness include rash and arthralgia [24], Guillain-Barre syndrome [31, 32], myasthenia gravis [33], bilateral brachial neuritis, peripheral neuralgia with meningitis, seizures, nerve palsies, and pseudotumor cerebri.

5.1. Chronic Hepatitis. Chronic HEV infection by definition requires elevated aminotransferase levels, positive serum HEV RNA, and suggestive histologic findings for at least 3 months [3]. It is usually caused by genotype 3 and chronic infection secondary to genotypes 1 and 2 has not been documented [4]. One case of chronic HEV infection by genotype 4 has been reported in the literature [20]. Risk factors include immunosuppression, solid organ transplantation, HIV infection, hemodialysis, and hematological malignancies $[1,3,4,17,34-40]$. 
The route of transmission is not different from that seen in acute infection [3]. Most patients are either asymptomatic or present with vague symptoms. Extraintestinal manifestations neuralgic amyotrophy [41], peripheral neuropathies, encephalitis [32, 42], encephalopathy [32, 43], ParsonageTurner syndrome [42], paroxysmal myopathy, and bilateral pyramidal syndromes are known to occur [1].

Presence of chronic infection in immunocompromised patients carries a bad prognosis which if left untreated rapidly progresses to cirrhosis (10\% in 2 years) and end-stage liver disease (ESLD) $[1,13]$.

5.2. HEV Infection during Pregnancy. HEV infection during pregnancy is associated with increased risk of prematurity, abortion, low birth weight, perinatal mortality, fulminant hepatitis, and maternal mortality [6]. Maternal mortality rates are highest during the third trimester and have been reported to be as high as $25 \%$ [3]. Interestingly, in some countries such as Egypt, HEV infection during pregnancy is not associated with increased mortality. This phenomenon can likely be explained by the fact that the predominant genotype is less virulent [3].

\section{Diagnosis}

Clinical signs, symptoms, and laboratory findings often overlap with hepatitis from other etiologies and make confirmation of diagnosis difficult. Some experts suggest that testing for hepatitis E should be part of the diagnostic algorithm for all patients with acute or chronic hepatitis that cannot be explained by other causes [8].

Diagnostic methods are broadly classified into two types: direct and indirect. The direct methods detect the virus, viral proteins, or nucleic acids in blood and stool samples by immune-electron microscopy and RT-PCR. The indirect methods detect the anti-HEV IgM and IgG antibodies [1].

Detection of anti-HEV IgM is considered diagnostic for acute infection. The presence of IgG antibodies points out to previous exposure to HEV [4]. Anti-HEV IgM is detectable 4 days after the onset of jaundice and persists for up to 3-5 months [6]. Shortly after the appearance of IgM, IgG antibodies develop and peak at about 4 weeks after the onset of symptoms and persist for a variable period of 1 to 14 years after infection [6].

The detection of HEV RNA in biologic specimen (serum and/or stools) is the "gold standard" for the confirmation of acute HEV infection [9]. HEV RNA can be detected in stools 1 week before and up to 6 weeks after the onset of symptoms and in serum for 3-4 weeks from the onset of illness $[4,7]$.

The sensitivity of molecular tests for the detection of HEV RNA is dependent on how early the patient presents, timely collection of specimens along with its rapid transport, processing, and viral genotype inclusivity. Therefore, undetectable HEV RNA does not rule out recent infection [4].

PCR assays published so far have a high degree of performance variability. Therefore, World Health Organization (WHO) has recommended an international standard for HEV RNA detection and quantification that uses genotype $3 \mathrm{a}$ due to its worldwide distribution and its detection in chronic infections $[3,4,6]$. Another nucleic acid amplification technique, the loop-mediated isothermal amplification (LAMP) assay, has been developed for the detection of HEV RNA. The LAMP assay is quicker than real-time PCR and does not need special equipment, making it ideal for resource limited areas [3].

Insensitive and unspecific diagnostic tests for anti-HEV antibodies have made diagnosis challenging. In a study, in only $13.3 \%$ of the samples, anti-HEV IgM serology correlated to $\mathrm{HEV}$ polymerase chain reaction (PCR) positivity. This demonstrates an extremely low level of correlation with PCRconfirmed HEV infections [6]. Furthermore, false reactivity for anti-HEV IgM with Epstein-Barr virus (EBV) and cytomegalovirus (CMV), $33.3 \%$ and $24.2 \%$, respectively, has been expressed in a study [6]. This is a clinically important consideration because these viruses form the differential diagnosis for acute non-A, non-B hepatitis. Nonetheless, recently developed "point-of-care" assays for anti-HIV IgM are simple, rapid, highly sensitive, and specific, ideal for resource-limited areas [3, 44]. Recently, novel efficient cell cultures have been generated for HEV3(4) and HEV4(3) that permitted the propagation of HEV in fecal and serum samples [3]. This discovery will be indispensable for extracting the infectivity titers of inocula in the future [3].

Anti-HEV-IgG and -IgM are fairly reliable methods of diagnosis in immune-competent hosts. However, they are frequently false-negative in immunocompromised host, which imposes a diagnostic challenge. RT-PCR is recommended to diagnose HEV infection in this subset of patients. In this setting, HEV RNA detection and quantification also has a role in monitoring response to antiviral therapy and determining the genotype of HEV involved $[4,5,7,9]$. Nucleic acid amplification technology methods by RT-PCR have been demonstrated as having a higher sensitivity when compared to HEV IGM and HEV antigen. They are therefore better screening tests [45].

\section{Treatment}

Acute hepatitis E usually does not require treatment in immune-competent individuals. Data on treatment of $\mathrm{HEV}$ in immunocompromised, frequently chronic hepatitis is sparse, and, therefore, patient tailored therapy is the best option.

If HEV RNA persists for 3 months, then the patient is very unlikely to achieve spontaneous viral clearance without therapeutic intervention [3]. The most important step that should be considered is whether immunosuppression can be reduced. A study reports $25 \% \mathrm{HEV}$ clearance rates by this strategy [46]. However, chances of transplant organ rejection greatly increase when immunosuppression is reduced. So, it can be rightly called a double-edged sword. Additionally, pegylated interferons have been used fairly successfully at times but are associated with significant side effects. They are better options in transplant recipients where reducing immunosuppression is not an option. Another somewhat promising option is ribavirin therapy. Ribavirin has been 
used to successfully treat severe acute hepatitis E patients with compromised immune systems [47]. Although there is no convincing data on it yet to make it a standardized option of HEV treatment, two French studies have shown virologic responses in 2 out of 2 and 4 out of 6 patients, respectively [48, 49]. However ribavirin is contraindicated in pregnancy. Liver transplant is the only option in patients who get fulminant hepatic failure.

\section{Vaccination}

Should one be infected by hepatitis E and recover, he or she will get protective immunity, with the courtesy of CD4 and CD8 T cells. Another way to induce immunity is via vaccination [50]. The HEV vaccine which is in the most advanced stages of development is HEV 239. It is a Chinese manufactured vaccine that has a $94-100 \%$ efficacy in a phase III trial conducted on more than 100,000 Chinese soldiers. Although it is based on the type 1 genotype, it works even against genotypes 1 and 4 . Response to genotype 3 is not known. It is still in the development stage to be used worldwide but has been approved for use in China [51].

\section{Conclusion}

Keeping in view the history of identification of HEV, that is, a water-borne epidemic of acute hepatitis in a developing country, today, hardly few decades from its diagnosis, we can hardly limit it to "acute," "hepatic," "water-borne," "epidemic," or "developing" settings.

Recent identification of chronic HEV in immunosuppressed cases and its extrahepatic presentation manifests how limited our knowledge about HEV has been. One cannot stop wondering, "Do we know all about Hepatitis E?" We can no longer underestimate the importance of further research on the virus that had taken us off guard.

The fact that HEV is a common cause of acute hepatitis worldwide and recent appearance of many cases of acute hepatitis caused by HEV being misdiagnosed for causes such as drug-induced hepatitis, HEV testing should be considered among the first line when evaluating acute liver injury.

High mortality in pregnant females due to HEV and chronic HEV hepatitis in immunosuppressed cases and in those with underlying chronic liver disease expresses the urgent need of appropriate measures aimed at improving the current state of diagnosis and treatment of HEV.

Also, unexpectedly high seroprevalence in blood donors proclaims that emphasis be laid on consideration of screening of $\mathrm{HEV}$ in blood donors. And probably the first step would be to call attention to development of standardized diagnostic tests that have higher sensitivity and specificity and are costeffective and commercially available.

\section{Conflict of Interests}

The authors declare that there is no conflict of interests regarding the publication of this paper.

\section{References}

[1] S. Fujiwara, Y. Yokokawa, K. Morino, K. Hayasaka, M. Kawabata, and T. Shimizu, "Chronic hepatitis E: a review of the literature," Journal of Viral Hepatitis, vol. 21, no. 2, pp. 78-89, 2014.

[2] C. Féray, J.-M. Pawlotsky, A.-M. Roque-Afonso, D. Samuel, and D. Dhumeaux, "Should we screen blood products for hepatitis e virus RNA?" The Lancet, vol. 383, no. 9913, p. 218, 2014.

[3] N. Kamar, H. R. Dalton, F. Abravanel, and J. Izopet, "Hepatitis E virus infection," Clinical Microbiology Reviews, vol. 27, no. 1, pp. 116-138, 2014.

[4] J. E. Arends, V. Ghisetti, W. Irving et al., "Hepatitis E: an emerging infection in high income countries," Journal of Clinical Virology, vol. 59, no. 2, pp. 81-88, 2014.

[5] N. Kamar, R. Bendall, F. Legrand-Abravanel et al., "Hepatitis E," The Lancet, vol. 379, pp. 2477-2488, 2012.

[6] S. Mirazo, N. Ramos, V. Mainardi, S. Gerona, and J. Arbiza, "Transmission, diagnosis, and management of hepatitis E: an update," Journal of Hepatic Medicine: Evidence and Research, vol. 6, pp. 45-59, 2014.

[7] M. T. Pérez-Gracia, B. Suay, and M. L. Mateos-Lindemann, "Hepatitis E: an emerging disease," Infection, Genetics and Evolution, vol. 22, pp. 40-59, 2014.

[8] S. Pischke and H. Wedemeyer, "Hepatitis E virus infection: multiple faces of an underestimated problem," Journal of Hepatology, vol. 58, no. 5, pp. 1045-1046, 2013.

[9] J.-M. Echevarría, "Light and darkness: prevalence of hepatitis E virus infection among the general population," Scientifica, vol. 2014, Article ID 481016, 14 pages, 2014.

[10] N. Kamar, R. Bendall, F. Legrand-Abravanel et al., "Hepatitis E," The Lancet, vol. 379, no. 9835, pp. 2477-2488, 2012.

[11] H. R. Dalton, J. G. Hunter, and R. Bendall, "Autochthonous hepatitis e in developed countries and HEV/HIV coinfection," Seminars in Liver Disease, vol. 33, no. 1, pp. 50-61, 2013.

[12] P. Colson, P. Borentain, B. Queyriaux et al., "Pig liver sausage as a source of hepatitis e virus transmission to humans," The Journal of Infectious Diseases, vol. 202, no. 6, pp. 825-834, 2010.

[13] H. R. Dalton, "Hepatitis E: the 'new kid on the block' or an old friend?" Transfusion Medicine and Hemotherapy, vol. 41, no. 1, pp. 6-9, 2014.

[14] P. C. Y. Woo, S. K. P. Lau, J. L. L. Teng et al., "New hepatitis E virus genotype in camels, the Middle East," Emerging Infectious Diseases, vol. 20, no. 6, pp. 1044-1048, 2014.

[15] C. Alvarado-Esquivel, L. F. Sanchez-Anguiano, and J. Hernandez-Tinoco, "Seroepidemiology of hepatitis E virus infection in general population in rural durango, Mexico," Hepatitis Monthly, vol. 14, no. 6, Article ID e16876, 2014.

[16] S. Kumar, S. Subhadra, B. Singh, and B. K. Panda, "Hepatitis E virus: the current scenario," International Journal of Infectious Diseases, vol. 17, no. 4, pp. e228-e233, 2013.

[17] T. M. Pavri, D. A. Herbst, and K. R. Reddy, "Chronic hepatitis E virus infection: challenges in diagnosis and recognition in the United States," Journal of Clinical Gastroenterology, vol. 49, no. 1, pp. 86-88, 2014.

[18] F. Montella, G. Reza, F. di Sora, P. Pezotti, and O. Recchia, "Association between hepatitis E virus and HIV infection in homosexual men," The Lancet, vol. 344, no. 8934, p. 1433, 1994.

[19] B. A. I. Payne, M. Medhi, S. Ijaz et al., "Hepatitis E virus seroprevalence among men who have sex with men, United Kingdom," Emerging Infectious Diseases, vol. 19, no. 2, pp. 333335, 2013. 
[20] Y. Geng, H. Zhang, W. Huang et al., "Persistent hepatitis E virus genotype 4 infection in a child with acute lymphoblastic leukemia," Hepatitis Monthly, vol. 14, no. 1, Article ID e15618, 2014.

[21] J. H. Hoofnagle, K. E. Nelson, and R. H. Purcell, "Current concept hepatitis E," The New England Journal of Medicine, vol. 367, pp. 1237-1244, 2012.

[22] C. L. Crossan, K. J. Simpson, D. G. Craig et al., "Hepatitis E virus in patients with acute severe liver injury," World Journal of Hepatology, vol. 6, no. 6, pp. 426-434, 2014.

[23] S. Haim-Boukobza, A. Coilly, M. Sebagh et al., "Hepatitis E infection in patients with severe acute alcoholic hepatitis," Liver International, 2014.

[24] I. Al-Shukri, E. Davidson, A. Tan et al., "Rash and arthralgia caused by hepatitis E," The Lancet, vol. 382, no. 9907, p. 1856, 2013.

[25] J. Price, "An update on hepatitis B, D, and E viruses," Topics in Antiviral Medicine, vol. 21, no. 5, pp. 157-163, 2013.

[26] D. B. Smith and P. Simmonds, "Hepatitis E virus and fulminant hepatitis-a virus or host-specific pathology?” Liver International, 2014.

[27] J. H. Hoofnagle, K. E. Nelson, and R. H. Purcell, "Hepatitis E," The New England Journal of Medicine, vol. 367, no. 13, pp. 12371244, 2012.

[28] R. Aggarwal Jr., "Epidemiologic concerns and advances in knowledge on hepatitis E," Gastroenterology \& Hepatology, vol. 9, no. 3, pp. 173-175, 2013.

[29] I. Masood, A. Rafiq, and Z. Majid, "Hepatitis E presenting with thrombocytopaenia," Tropical Doctor, vol. 44, no. 4, pp. 219220, 2014.

[30] S.-J. Huang, X.-H. Liu, J. Zhang, and M.-H. Ng, "Protective immunity against HEV," Current Opinion in Virology, vol. 5, pp. $1-6,2014$.

[31] T. Comont, D. Bonnet, N. Sigur, A. Gerdelat, F. LegrandAbravanel, N. Kamar et al., "Acute hepatitis E infection associated with Guillain-Barré syndrome in an immunocompetent patient," La Revue de Medecine Interne, vol. 35, no. 5, pp. 333336, 2014.

[32] X. Wu, K. Liu, and H. L. Zhang, "Guillain-Barré syndrome and encephalitis/encephalopathy associated with acute severe hepatitis E infection," Neurological Sciences, 2014.

[33] A. Belbezier, A. Deroux, F. Sarrot-Reynauld, S. Larrat, and L. Bouillet, "Myasthenia gravis associated with acute hepatitis E infection in immunocompetent woman," Emerging Infectious Diseases, vol. 20, no. 5, pp. 908-910, 2014.

[34] N. Kamar, J. Selves, J.-M. Mansuy et al., "Hepatitis E virus and chronic hepatitis in organ-transplant recipients," The New England Journal of Medicine, vol. 358, no. 8, pp. 811-817, 2008.

[35] X. Zhou, R. A. de Man, R. J. de Knegt, H. J. Metselaar, M. P. Peppelenbosch, and Q. Pan, "Epidemiology and management of chronic hepatitis E infection in solid organ transplantation: a comprehensive literature review," Reviews in Medical Virology, vol. 23, no. 5, pp. 295-304, 2013.

[36] H. R. Dalton, R. P. Bendall, F. E. Keane, R. S. Tedder, and S. Ijaz, "Persistent carriage of hepatitis E virus in patients with HIV infection," The New England Journal of Medicine, vol. 361, no. 10, pp. 1025-1027, 2009.

[37] Z. Abbas and R. Afzal, "Hepatitis E: when to treat and how to treat," Antiviral Therapy, vol. 19, no. 2, pp. 125-131, 2014.

[38] M. T. Giordani, P. Fabris, E. Brunetti, S. Goblirsch, and L. Romanò, "Hepatitis E and lymphocytic leukemia in man, Italy," Emerging Infectious Diseases, vol. 19, no. 12, pp. 2054-2056, 2013.
[39] Y. Wang, H. J. Metselaar, M. P. Peppelenbosch, and Q. Pan, "Chronic hepatitis E in solid-organ transplantation: the key implications of immunosuppressants," Current Opinion in Infectious Diseases, vol. 27, no. 4, pp. 303-308, 2014.

[40] N. Kamar and J. Izopet, "Does chronic hepatitis E virus infection exist in immunocompetent patients?” Hepatology, vol. 60, no. 1 , p. 427, 2014.

[41] J. J. van Eijk, R. G. Madden, A. A. van der Eijk et al., "Neuralgic amyotrophy and hepatitis E virus infection," Neurology, vol. 82, no. 6, pp. 498-503, 2014.

[42] A. Deroux, J. P. Brion, L. Hyerle et al., "Association between hepatitis $\mathrm{E}$ and neurological disorders: two case studies and literature review," Journal of Clinical Virology, vol. 60, no. 1, pp. 60-62, 2014.

[43] M. A. de Vries, J. P. A. Samijn, R. de Man, and J. M. M. Boots, "Hepatitis E-associated encephalopathy in a renal transplant recipient," BMJ Case Reports, 2014.

[44] D. J. Seo, H. Tahk, K. B. Lee et al., "Detecting hepatitis E virus with a reverse transcription polymerase chain reaction enzyme-linked immunosorbent assay," Food and Environmental Virology, vol. 4, no. 1, pp. 14-20, 2012.

[45] T. Vollmer, C. Knabbe, and J. Dreier, "Comparison of real-time PCR and antigen assays for detection of hepatitis e virus in blood donors," Journal of Clinical Microbiology, vol. 52, no. 6, pp. 2150-2156, 2014.

[46] N. Kamar, F. Abravanel, J. Selves et al., "Influence of immunosuppressive therapy on the natural history of genotype 3 hepatitis-e virus infection after organ transplantation," Transplantation, vol. 89, no. 3, pp. 353-360, 2010.

[47] A. Robbins, D. Lambert, F. Ehrhard et al., "Severe acute hepatitis E in an HIV infected patient: successful treatment with ribavirin," Journal of Clinical Virology, vol. 60, no. 4, pp. 422423, 2014.

[48] N. Kamar, L. Rostaing, F. Abravanel et al., "Ribavirin therapy inhibits viral replication on patients with chronic hepatitis $\mathrm{E}$ virus infection," Gastroenterology, vol. 139, no. 5, pp. 1612-1618, 2010.

[49] V. Mallet, E. Nicand, P. Sultanik et al., "Brief communication: case reports of ribavirin treatment for chronic hepatitis E," Annals of Internal Medicine, vol. 153, no. 2, pp. 85-89, 2010.

[50] H. Wedemeyer, S. Pischke, and M. P. Manns, "Pathogenesis and treatment of hepatitis E virus infection," Gastroenterology, vol. 142, no. 6, pp. 1388.e1-1397.e1, 2012.

[51] F.-C. Zhu, J. Zhang, X.-F. Zhang et al., "Efficacy and safety of a recombinant hepatitis e vaccine in healthy adults: a large-scale, randomised, double-blind placebo-controlled, phase 3 trial," The Lancet, vol. 376, no. 9744, pp. 895-902, 2010. 


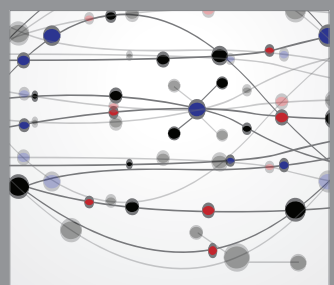

The Scientific World Journal
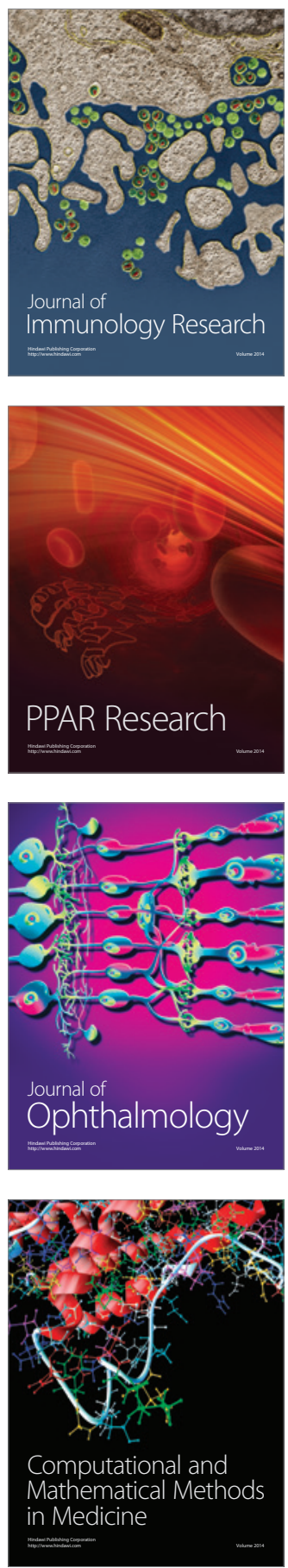

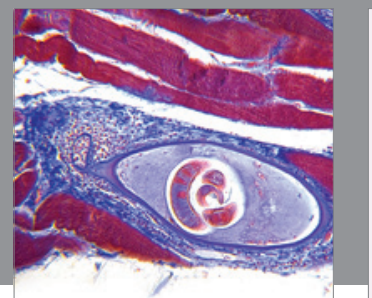

Gastroenterology

Research and Practice
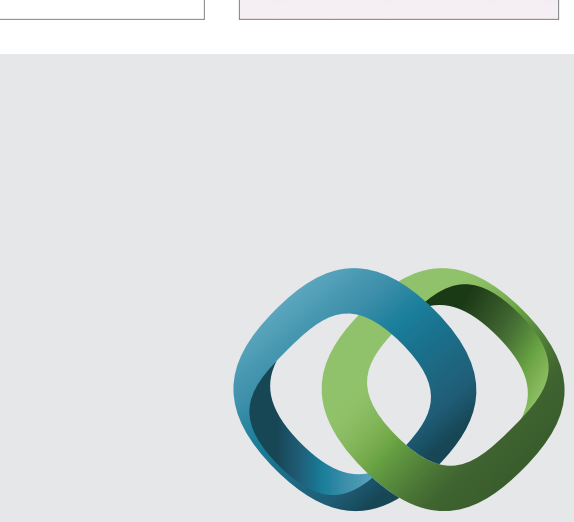

\section{Hindawi}

Submit your manuscripts at

http://www.hindawi.com
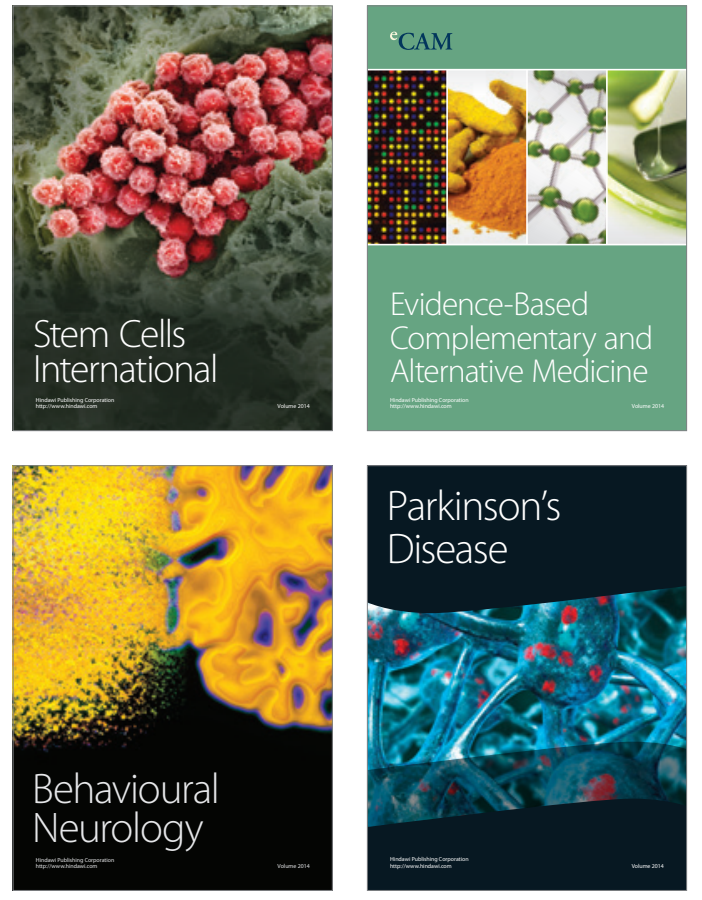
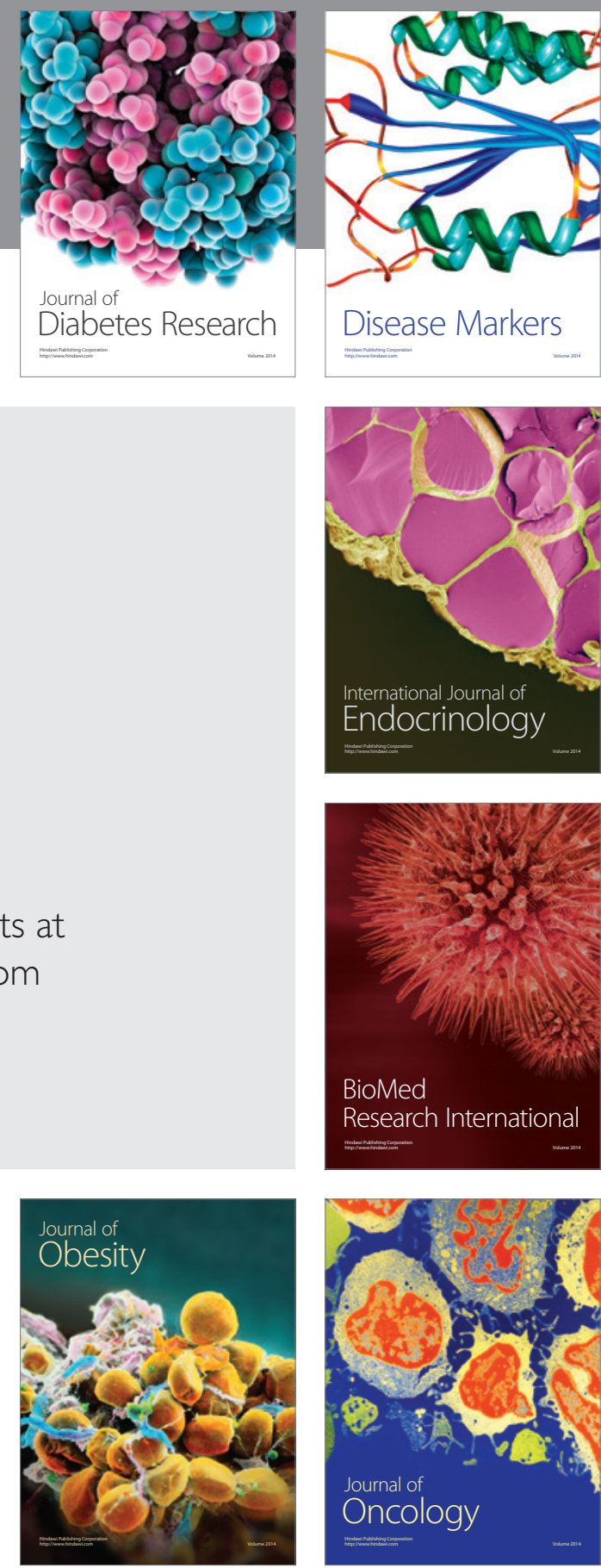

Disease Markers
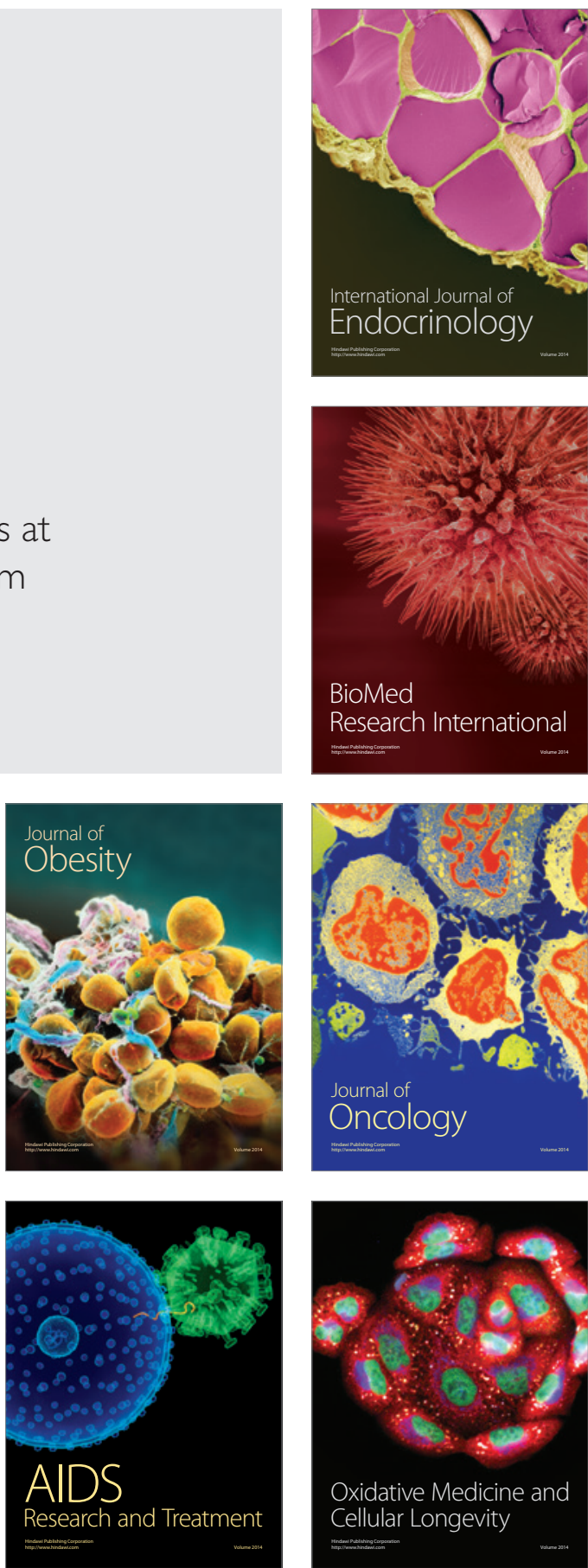